\title{
Are Sexual Victims Less Likely to be Accepted by Their Boyfriends?-A Comparison Between Sexually Invaded Women and Women with Voluntary Sexual Behavior
}

\author{
Zhaoyuan Zhang ${ }^{1}$, Dan Huang ${ }^{1}$, Yuxia $\mathrm{Liu}^{2}$, Yahui Chen ${ }^{1}$ and Xia $\mathrm{Zu}^{1}{ }^{1, *}$ \\ ${ }^{1}$ School of Management, Chengdu University of Information Engineering, Chengdu, Sichuan 610103, China \\ ${ }^{2}$ Nanjing University of Posts and Telecommunications, Nanjing, Jiangsu 210003, China \\ *Correspondence author. Email: sunnyzu@163.com
}

\begin{abstract}
Sexual assault cases occur frequently, and the number of victims of sexual assault continues to rise. This paper investigates the acceptability in marriage and love relationship of "non-virgins" such as women who have premarital sex and victims of sexual assault through questionnaires and analyzing relevant comments from Sina Weibo (A Chinese social platform). Using the SPSS software to conclude that "a sexually assaulted girlfriend" (28.1\%) is more unacceptable than "a girlfriend who has had sexual experience" (13.1\%). This article will provide a simple analysis of the reasons why victims of sexual assault are less likely to be accepted among the two types of "non-virgin" women under the influence of the "virginity obsession". And we make recommendations to improve the unfair treatment of sexual assaulted women.
\end{abstract}

Keywords: virginity obsession, victim of sexual assault, the ideal victim, premarital sex

\section{INTRODUCTION}

In the process of social development, sexual liberation from the west has affected Chinese chastity concept to a certain extent. But Chinese chastity concept has still oppressed women in various aspects of social life. The most prominent is the 'virginity obsession' which has been deeply rooted in the hearts of generations since the establishment of the feudal system. Although the number of non-virgins is gradually increasing because of the increase of sexual relationship among the youth, most of the girls still worry that their non-virginity will have a negative impact on their future married life, which also contributed to the rise of the 'hymen repair surgery' . In recent years, many well-known scholars, such as Li Yinhe, have explained and evaluated the emergence, development and influence of the 'virginity obsession'. They have affirmed the contemporary women access to sexual freedom and sexual liberation. However, it shows that the discussion of the non-virgin label women who are the victims of sexual assault is minimal in the research about women chastity and 'virginity obsession'.

At present, after the basic needs of human beings have been met, the desire for sex has become stronger, so the cases of sexual assault have occurred frequently. The group of victims of sexual assault is special but not small. However, data mining through comments on Sina Weibo's topic of sexual assault shows that the society has a large prejudice against victims of sexual assault. Although people have more sympathetic attitudes towards victims of sexual assault, there are no fewer cases of scrutiny and questioning. To this end, this article conducted a questionnaire survey and interviews on the assumption that the respondent's girlfriend had experienced sexual assault or had sexual relations with her predecessor. It shows that men were less likely to accept that their girlfriend had been sexually assaulted. Women with the same label of 'non-virgin' who are victims of sexual assault are less likely to be accepted by their boyfriends and the society than women who have sex with their predecessors. This article analyzes the reasons why men are more difficult to accept their girlfriends who have been sexually assaulted and makes recommendations to improve the unfair situation faced by victims of sexual assault.

\section{PARTICIPANT AND METHOD}

Through the online questionnaire publishing method, a total of 1034 questionnaires were retrieved, of which 976 were valid questionnaires. There were 420 males and 556 females in the valid questionnaire. The respondents were $16-25$ years old, of which 16-18 years old accounted for $13.8 \%$, and $18-25$ years old accounted for $86.2 \%$. Most of the respondents were located in cities $(66.1 \%)$, and a small number were from rural areas (15.6) and urban-rural integration area(18.3\%). Among the respondents, there were $69.2 \%$ of undergraduates, $13.8 \%$ of high school graduates, $12.2 \%$ of masters and above, $2.7 \%$ of junior college students, and $2.2 \%$ of junior high school and below.

The collected network questionnaire data is imported into the SPSS.21 software, and the data is analyzed by descriptive statistics and the $\chi^{2}$. For the blog about sexual assault on Sina Weibo, this article uses Python crawler technology to mine data on the comments below the more prominent blog. And the statistics of the keyword frequency 
of each blog are counted. These words frequency combines the frequency of occurrence of the words and the number of times they are praised. Finally, the data were analysed and visualized.

\section{INVESTIGATION AND ANALYSIS}

\subsection{Current Status of "Virginity Obsession"}

The 'virginity obsession' refers to a psychological orientation of a male to a female before marriage[1]. This is not only the expression of loyalty to love between men and women, but also the product of patriarchalism under feudal rule. The 'virginity obsession' is a symbol of male expectation of full possession of women and a desire for a partner as a private property. 'Non-virgin' includes both women who have sex spontaneously and victims of unfortunate sexual assault. The term 'sexual assault' refers to the forced sexual relationship with others, that is, rape in the legal sense. At the same time, the victims of sexual assault in this article are female victims.

In this survey, all female subjects assumed that they were male. The survey content is that among the women who have experienced sexual assault or who have sex with their predecessors, which one is more unacceptable for their boyfriend. Displayed in the survey that $42.01 \%$ of the subjects said that 'it is indifferent and acceptable', 28.07\% of the subjects chose 'girlfriend had been sexually assaulted', and $13.11 \%$ of the subjects chose 'girlfriend and predecessor had sexual intercourse', $16.80 \%$ of the subjects chose 'The above two situations are unacceptable'. Under this assumption, it is worth noting that the 'virginity obsession' still exists in most people(57.99\%), as shown in Figure 1.

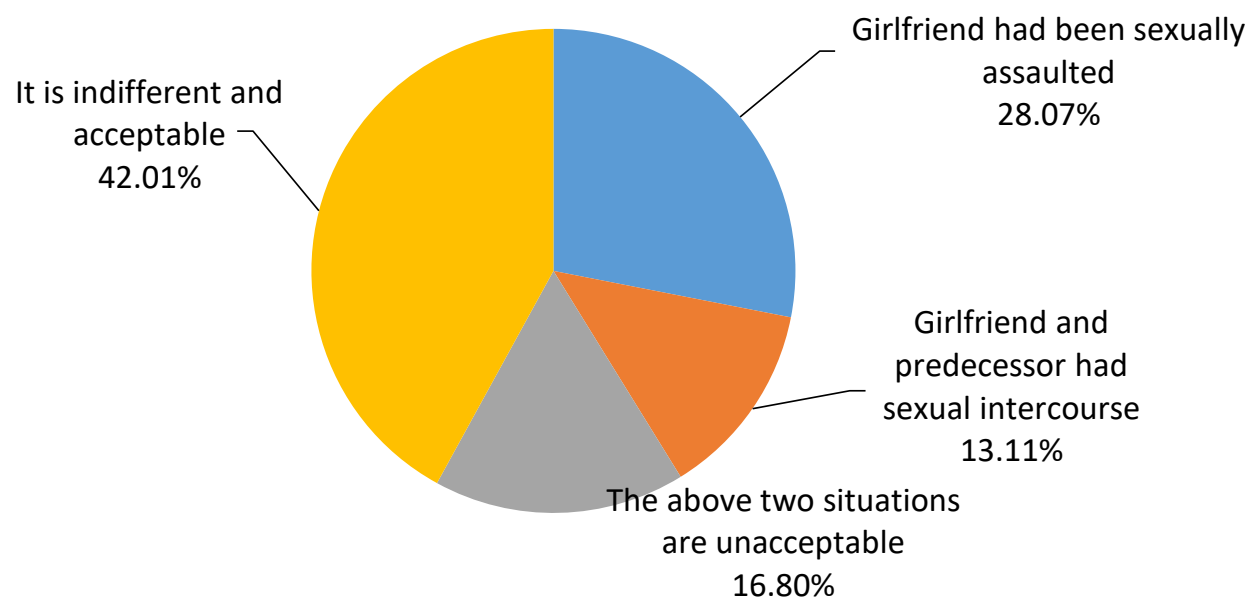

Figure 1. The acceptance of a girlfriend who have experienced sexual assault or who have sex with their predecessors

From the data we can get, in the open society with sexual freedom, people's minds about 'virgins' have been greatly changed. Men in the marriage and love can also naturally accept 'non-virgin' partners. This reflects not only the acquisition of female sexual freedom, but also the result of the maintenance of women's rights. The reason for the gradual weakening of the 'virginity obsession' is that women's social status has been significantly improved and more and more women are moving towards society and are able to actively compete for many jobs. Secondly, due to the freedom of marriage and love, the long-time interval between the maturity age and the legal age of marriage, the normal physiological needs of men and women should be met in daily relationships; Third, because the cultural products of the mass media, such as film and television dramas, the image of women's dare to love and hate has increased, and the film and television dramas of premarital sex are not rare, which has reduced the prejudice against 'non-virgins'. However, the current society is influenced by the male-dominated culture and the traditional concept of virginity. The 'virginity obsession' still exists in the hearts of most people.

\subsection{Sexual Assault Victims are Less Likely to be Accepted by Their Boyfriends}

The victims of sexual assault and the women who have had sexual relations with their predecessors are all 'non-virgins' in traditional culture. However, through the analysis of the survey data, it is found that people are more unacceptable to their girlfriends who have been sexually assaulted. That is, in a relationship of love, it is more unacceptable to be told that a man's girlfriend is a sexually assaulted $\operatorname{victim}(28.07 \%)$ than his girlfriend had sexual relations with his predecessor $(13.11 \%)$. They are called 'non-virgins' 
similarly, but victims of sexual assault are not accepted by their partners. The former belongs to being forced to have sexual relations with others, and the latter is voluntary. However, it is clear that the general public is more likely to accept voluntary person rather than forced victims. And there is a significant difference in perceptions of this hypothesis between different genders $(\mathrm{P}=0.000)$, which is statistically significant. The data shows that men have higher choices than women among the three options such as girlfriend was sexually assaulted (28.6\%), girlfriend and her predecessor had sexual intercourse $(15.0 \%)$ and both were unacceptable $(21.7 \%)$. The percentage of women who do not care both cases $(47.5 \%)$ is significantly higher than men (34.8\%). As shown in Table 1.

Table 1. The acceptance in different gender of a girlfriend who have experienced sexual assault or who have sex with their predecessors.

\begin{tabular}{|c|c|c|c|c|}
\hline \multirow{2}{*}{ Options } & \multicolumn{2}{|l|}{ Gender } & \multirow{2}{*}{$\chi^{2}$} & \multirow{2}{*}{$\mathrm{p}$-value } \\
\hline & Male & Female & & \\
\hline $\begin{array}{l}\text { Girlfriend had been sexually } \\
\text { assaulted }\end{array}$ & $120(28.6)$ & $154(27.7)$ & 21.656 & 0.000 \\
\hline $\begin{array}{l}\text { Girlfriend and predecessor } \\
\text { had sexual intercourse }\end{array}$ & $63(15.0)$ & $65(11.7)$ & & \\
\hline $\begin{array}{l}\text { The above two situations are } \\
\text { unacceptable }\end{array}$ & $91(21.7)$ & $73(13.1)$ & & \\
\hline $\begin{array}{l}\text { It is indifferent and } \\
\text { acceptable }\end{array}$ & $146(34.8)$ & $264(47.5)$ & & \\
\hline
\end{tabular}

In the selection data that have significant differences between different genders, women have lower probabilities than men for choosing the two options of 'girlfriend has been sexually abused' and 'girlfriend had sexual intercourse'. But in the case of option 'Indifferent, I can accept both', the number of women is more than men. From this hypothetical choice, women pursuit of sexual rights, sexual freedom and the desire for equality between men and women can be seen. Sorting the choices of men under this hypothesis from high to low, the highest percentage is 'Indifferent, I can accept both', followed by 'girlfriend has been sexually abused', and again 'the above two cases are unacceptable' The least is that 'girlfriend has had sexual relations with her predecessor'. It is not difficult to see from the above data that men are more unacceptable that their girlfriends have been sexually assaulted. After the assumptions, it can also be found that women in the subconscious also believe that men are more unacceptable that their girlfriends had been sexually assaulted. This phenomenon may be caused by the following reasons:

\subsubsection{The prevalence of premarital sex and the particularity of sexual assault}

Premarital sex is a social phenomenon that is popular in the contemporary era. It is a part of the majority of men and women who are in love. The phenomenon is more common in men and women with emotional foundation. Sexual assault has been a criminal act since ancient times. Sexual assaults only exist among some unfortunate victims and have special characteristics. At the same time, because sexual assault has continued since the ancient conception of the chastity, it is closely tied with the concept of chastity. Although the concept of chastity is superficial in the contemporary open environment, it is still deeply rooted in many people's minds. While women who are premarital sex are 'non-virgins', the men who have sex with these women may become their legal husbands. The chastity of such women can be compensated from the male views; In addition to the existence of compulsory marriages for victims and offenders of sexual assault in ancient and contemporary remote areas, victims and offenders in other situations are almost impossible to marry. Even if the perpetrator is an acquaintance and has a feeling for the victim, it is difficult for the victim to get rid of the mental torture of the self.

\subsubsection{Sexual assault hypothesis and male dignity frustrated}

There are two main male sexual assault hypotheses, one is the conditional hypothesis, and the other is the resistance hypothesis. In the case of a sexual assault case, a sexually aggressive environment is often pre-set. That is, the time, the place, and the clothing of the victims are increasing the probability of sexual assault, creating favorable conditions for the perpetrators. Even in some people's eyes, the time, the place, and the clothing of the victims of sexual assault are seduce the perpetrators. Men are more likely than women to believe in the myth of rape, such as a girl's sexy dress is a symbol of 'I can have a sex with you.' [2]. The above is a conditional assumption; In the face of the perpetrators, the male sexual resistance hypothesis assumes that the victim should be screaming, struggling, asking for 
help, or even dying, as in the image of a mistress created in many TV dramas. If one is fortunate to be healthy and alive, then she is only suffering a voluntary sexual activity rather than sexual assault.

In ancient China, the equalization of women chastity to men loyalty is a very special point in moral dogma. The entire Chinese tradition has such a tradition. When the bad atmosphere is prevalent, the promotion of traditional ethics will be highly valued. When the status of the ruling class is threatened by foreign aggression, or when the invasion of foreigners causes the traditional Chinese culture to be destroyed, the banner of ethics and loyalty will be exalted. On the one hand, it is to praise the firmness and purity of women, on the other hand, it is to mock the weakness and incompetence of men[3]. From the self-satisfaction of men in patriarchal society, women loyalty to men makes men weak and incompetent self-cognitive psychological gaps or compensated by loyalty and gain a higher self-satisfaction. Back to the present, some scholars have suggested that men are tending toward 'second sex', which makes men start to fear. As women continue to expand into the realm of society, men at this stage are uneasy about the gender equality embodied in current economic development. It is considered that the victim appears under the condition of easily inducing sexual assault. The failure of resistance is the missing of the determination to maintain their own chastity, and the damage to the male private property. These two assumptions will undoubtedly hurt the male dignity of traditional patriarchalism and forced them to struggle constantly between the pity and the loss of dignity. It is difficult to face the victims of sexual assault with the original emotions.

\subsection{3. 'The ideal victim' and 'Slut shaming' - questioning the identity of the victims}

When the sexual assault case is reported, under the influence of people, under the influence of 'the ideal victim' and 'slut shaming', the victim's victim status is always questioned and weakened. The 'the ideal victim' was first mentioned in the book The Ideal Victim. It means that the characteristics of the perpetrator and the victim, as well as the criminal environment, will largely affect the public's level of sympathy for the victim, thereby giving the victim a incorrect status. Therefore, the ideal victim tends to be relatively weak, and the environment in which it is located does not make people criticize[4]. The so-called 'slut shaming' is a woman who, under the influence of traditional virginity, unconsciously thinks that other beautiful women, who have a lot of love, and who like to drink alcohol are women who have a confusing private life. That is to say, the sluts that the ancient society called the women who did not follow the woman's path. This are now being used as sophistication reasons by the victims of sexual assault.

In the case of sexual assault, people tend to pursue 'the ideal victim'. That is, victim wearing a conservative should encounter a very ferocious victim in a very safe environment, and the victim should make a strong resistance. Even after the victim was severely injured, she was unfortunately sexually abused. In order to cope with the primary and superficial imagination of innocent victims, people are even willing to sacrifice understanding of complex human nature and sacrifice professional analysis of the causes of crime. Once the polite sympathy tulle of 'viewing' is broken, the spectator of the public opinion field seems to have changed face instantly. They will maliciously speculate and injure the victim, and issue unfounded inferences, comments, ethical judgments unrelated to the case, and endlessly observe the victim with a human magnifying glass. They will ruthlessly whipping the socalled 'stains' discovered by no dead ends[4]. For example, a female teacher of Xi'an Siyuan College was sexually invaded for nearly a year. She was patient because she was afraid of losing her job because of her family's difficulties. Later, she couldn't stand and take evidence of sexual assault. In the Weibo commentary, the highest enthusiasm is the sympathy for the victim and the curse to the perpetrator. However, in the following comments, there is no lack of doubts about the victim after repeated sexual assaults. And it is suggested that the female teacher is for some kind of interest. As shown in Figure 2.

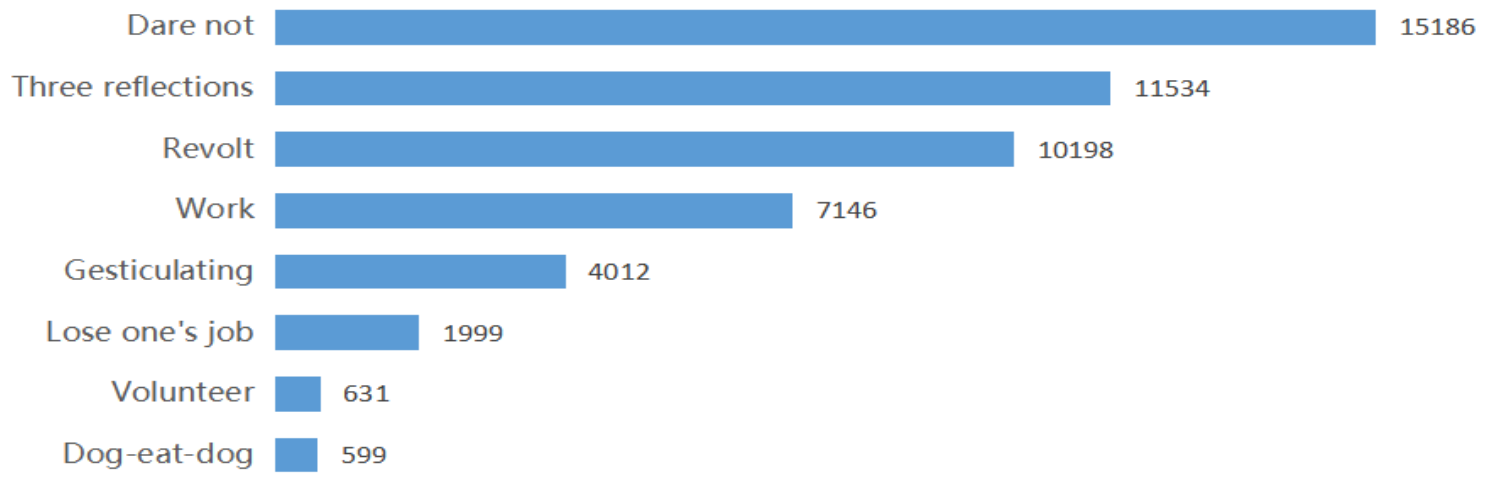

Figure 2. High frequency word from Sina Weibo comments 
In order to find a 'the ideal victim' and see a certain 'deficiency' of the victim, the public opinion has more focus on public opinion that can be discussed and can stand on the moral high ground. It is even possible to judge the victim's assertion that the victim was a misbehaving 'slut'. And under constant assumptions, the paradox is pushed to a peak that can crush the victims, because the victims at this time have also changed from victims to bad guys who are almost the same as the perpetrators. Such public opinion often turns into a sharp edge to insert the victim's self-esteem and selfconfidence and even the heart, and even the same kind of victims will encounter doubts and isolation from their husband. On the one hand, the victim will have doubts about himself because of public opinion. On the other hand, the opposite sex will also set the guiding content of public opinion to victims of sexual assault, making victims of sexual assault often in a more difficult position in marriage and love.

\subsubsection{Men are more likely to recognize that victims of sexual assault are unbearable and unclean}

According to the data, only a small number of young people $(25.1 \%)$ believe that victims of sexual assault are unbearable and unclean. At the same time, the perception that men think the victims of sexual assault is unbearable and unclean $(29.0 \%)$ is significantly higher than female $(22.1 \%)$. This is significantly different and statistically significant $(\mathrm{P}$ value $=0.013<0.05)$, as shown in Table 2 .

Although people are more positive about this view, there are significant differences between different genders in terms of negative attitudes. Men are more likely to think that women are unbearable and unclean after being sexually assaulted. It is believed that the victims of sexual assault are unbearable because of the influence of traditional ideas. It is believed that women should be pure and physically specific to men. If women are unfortunately misconducted and Sexual invasion by filthy people, men with mental cleanliness will more often transfer their filth to the victimized woman. And the victim's partner is severely frustrated by self-esteem, which also makes men less willing to accept victims of unfortunate sexual abuse.

Table 2. Gender differences in perceptions of whether sexual assault victims are unclean

\begin{tabular}{|c|c|c|c|c|}
\hline \multirow[b]{2}{*}{ Options } & \multicolumn{2}{|l|}{ Gender } & \multirow[b]{2}{*}{$\chi^{2}$} & \multirow[b]{2}{*}{$\mathrm{P}$-value } \\
\hline & Male & Female & & \\
\hline Yes & $122(29.0)$ & $123(22.1)$ & 6.103 & 0.013 \\
\hline No & $298(71.0)$ & 433(77.9) & & \\
\hline
\end{tabular}

Note: The number in () is the composition ratio /\%

\subsubsection{Affect the quality of normal couples' sexual life}

At present, the people's pursuit of a better life is accelerating. With the continuous advancement of sexual openness, contemporary youth no longer regard sex as an important part of the birth process but a important part of life. Therefore, young people have higher requirements for the quality of sexual life. When a partner has had sexual relations with a predecessor or has been sexually assaulted, it is easy to affect the harmony of sexual life. Among them, the men may worry that his partner is unforgettable to the predecessor. It will be uncomfortable to compare himself with the predecessor. If the partner has unfortunately been sexual invasion, It is mostly for both parties will feel uncomfortable. Most victims of sexual assault will suffer from Posttraumatic Stress Disorder. The so-called PTSD refers to the delayed or long-standing psychological or mental disorders caused by major psychological trauma. It mainly includes four symptoms clusters: invasive symptoms, avoidance symptoms, alertness symptoms and negative cognitive emotions[5]. When they are having sex, it is difficult for both partners to completely abandon negative thoughts, making it difficult for sexual life to be overwhelmed. This makes it more difficult for some men to accept victims of sexual assault in the face of two assumptions.

\section{THE PROPOSAL}

\subsection{Correctly Treat Victims of Sexual Assault}

The incidence of current sexual assaults does not decrease, although people's attitude towards victims of sexual assault has improved qualitatively. However, the unequal treatment of victims of sexual assault currently requires people to face sexual assault and victims. In the event of a sexual assault, we cannot rule out that the perpetrator is a temporary one. However, if the content of prevention of sexual assault is only from the wearing, travel time or entertainment location of the clothes, it can not only reduce the incidence of sexual assault, but also make the public aggravate the hypothesis of sexual assault. And put unfair pressure on the victims. In the discussion of sexual assault incidents, not only the government's attention but also the mass media's actions are needed. There are many ways for the mass media to communicate with the public. The most prominent is the 
information push on social platforms such as Weibo and WeChat. For example, the People's Daily Weibo reprinted the content of the speech by the Spanish Ines Hercovich lecturer on 'No consent is sexual assault': the current phenomenon of people's prejudice against victims of sexual assault and its causes. The People's Daily has been recognized by the majority of netizens.

\subsection{Break the Traditional View of Purity and Establish a Correct View of Marriage and Love}

The patriarchal culture that emerged with the establishment of male domination is characterized by gender discrimination and gender oppression. Men regard women as private goods and require women to be privatized to serve men. Therefore, many women as paragon of chastity have emerged in the traditional society, but there are no men. The concept of chastity under the inequality between men and women not only binds the female body, but also constrains the female mind. It is worth noting that the current contradictions are triggered by the current open sexual openness and the closed concept of women. That is, the male's general requirements for premarital behavior and the openness of marital derailment and the need for female chastity and the virginity obsession. Such unequal sexual ethical requirements are very unfair and are a poor manifestation of patriarchal rule. Gender equality should not be just a slogan, but a fundamental principle that both men and women should recognize.

Women should break the traditional weak feelings that women can only survive by relying on men, and establish the concept that contemporary women can survive independently. Women love the body for health, not to please the other half. Love or marriage, assuming a percentage system, if both or one of the parties is the first person to have physical contact, it should be an extra point other than the percentage, and should not be counted as a percentage.

\subsection{Improve the Victim Assistance System}

Sexual assault victims and their families often cause serious psychological trauma after this violent incident. Therefore, a corresponding psychological assistance institution should be established to provide psychological assistance to the victims and their families in time after the case occurs. At the same time, the assistance of the masses to the victims is also very important. The greatest harm suffered by many victims is sometimes not from sexual assaults, but the excessive sympathy of the surrounding public and the expectation of the 'the ideal victim'. This will force the victim to accept the traditional female ethical standards imposed by society. Therefore, the mass media should use their influence to convey to the public the correct treatment and how to scientifically help victims of sexual assault methods, instead of expressing the message "you are different from us" to the victims with compassion and compassion. In addition, the government should unite charitable organizations to carry out the transmission of rational morality in the community to improve the overall quality of the public and weaken the bad habits of the victims. To achieve "three no ones", that is, to treat victims and their families with contempt, no discussion, and no sympathy.

\subsection{Establish a Sexual Education System}

The popularity of sex education is expected to change the attitude and acceptance of current public treatment of victims of sexual assault and increase the rate of reporting. The content of sex education should not only protect potential victims from self-protection, but also protect and prevent coexistence, that is, focus on preventing sexual harassment and sexual assault while reducing the number of perpetrators. Through sex education, we can break through the inherent feudal conservative thoughts, liberate contemporary traditional women, and ensure the future progress of young people.

At present, a systematic sexual education system should be established to replace the simple, fragmentary and even non-scientific sex education in the past. At present, sexual education in China has regional imbalances, and there is a lack of sexual education corresponding to the stage of physiological development, and the main subjects of responsibility are not in place. It is time to establish a 'transitional sexual education system', that is, to pay attention to the scientific nature of sex education for parents and left-behind children at this stage. Raising the level of sexual knowledge of parents and popularizing correct sexual values and sexual ethics will not only help to improve the current attitude of the general public towards sexual harassment and sexual assault, but also to carry out the family education of the next generation of children. Schools and kindergartens carry out sex education according to the characteristics of students' physiological development stages. Rejecting lifelong education depends on one lesson, but should be well suited to the level of education required for students' physiological development.

\section{CONCLUSION}

Based on the above investigations and analysis, we can see the unfair attitude of the current society to treat victims of sexual assault, but also found that the impact of the current 'virginity obsession' is gradually weakening. We have reason to believe that by establishing a systematic sexual education system, we will establish a sound sexual morality and guide healthy public opinion. The prejudice and doubt faced by victims of sexual assault will gradually decrease in the future. As one of the important players in the social economy, women are entitled to the same rights as men, and they should and must include the right to freedom of sexual choice. 


\section{ACKNOWLEDGMENT}

This study is supported by major base projects (No.: SC20EZD009) in 2020 during the 13th Five-Year Plan of Sichuan Provincial Social Science Research.

\section{REFERENCES}

[1] Wang X. From the perspective of Goffman's 'staining' theory-Analysis of the issue of 'virgin obsession' in contemporary China[J]. Prose, 2018, (5):23-24.

[2] Kelly Welch. Sex! What you know you don't know, you should know[M]. 2014.
[3] Tian R. Male Anxiety and Female Chastity: A Comparative Study of Chinese Ethical Values in MingChing Times[M]. Brill, 1988.

[4] Zhang C. 'Idealized victim' Asking questions is detrimental to the health of public opinion[J]. Young reporter, 2017(28):95.

[5] American. Psychiatric, Association.(2013). Diagnostic and Statistical Manual of Mental Disorders (5th edition). Washington, DC: American Psychiatric Association.

[6] Yan D. Female studies[M]. China Federation of Literary Publishing House, 2001.

[7] Lu J. a protective umbrella for women's rights [J]. Citizen and the rule of law, 2017, 257(17): 4-6. 